\title{
ACOUSTICS2008/2357 \\ Conversion of a Scholte - Stoneley wave at the extremity of a fluid loaded plate: comparison between finite element method, radiation mode theory and experiments
}

\author{
E. Lamkanfia ${ }^{\mathrm{a}}$ N. F Declercq ${ }^{\mathrm{b}}$, W. Van Paepegem ${ }^{\mathrm{a}}$ and J. Degrieck ${ }^{\mathrm{a}}$ \\ ${ }^{a}$ Ghent University, Sint-Pietersnieuwstraat 41, 9000 Ghent, Belgium \\ ${ }^{\mathrm{b}}$ Georgia Tech Lorraine - G.W. Woodruff School of ME, UMI Georgia Tech - CNRS 2958, 2 rue Marconi, \\ 57070 Metz, France
}

The radiation theory has proved to produce results in agreement with experiments when the conversion is investigated of a Scholte - Stoneley wave at the extremity of a fluid loaded plate. The drawback of the radiation mode theory is that it is not universally applicable and is also very cumbersome. The advantage is that it is an exact method. There is a trend in acoustics to develop finite element models to describe the interaction of sound waves with materials. This investigation compares a newly developed finite element model to simulate the considered effect. Results are compared with the exact results obtained by the radiation mode theory [J. Acoust. Soc. Am. 101(3), 1347-1357, 1997] and experimental observations [J. Acoust. Soc. Am. 95(1), 13-20, 1994]. The study shows correspondence between the finite element analysis and earlier obtained experimental and theoretical results as a function of a relationship between mesh properties and the evanescence (rather than the wave length) of the considered Stoneley waves. 